\title{
Pinheirinho: do direito à cidade à reintegração de posse
}

\author{
Pinheirinho: from the right to the city to the repossession
}

Davi de Pinho Spilleir[a] (D)

[a] Pontifícia Universidade Católica de Campinas (PUC-Campinas), Programa de Pós-graduação em Sustentabilidade, Campinas, SP, Brasil

Como citar: Spilleir, D. P. (2019). Pinheirinho: do direito à cidade à reintegração de posse. urbe. Revista Brasileira de Gestão Urbana, 11, e20180004. https://doi.org/10.1590/2175-3369.011.e20180004

\section{Resumo}

Uma das necessidades mais elementares dos cidadãos é a da habitação. Não é possível almejar melhor qualidade de vida, promover uma série de outros direitos básicos sem que o cidadão esteja plenamente de posse de um lar que seja adequado, com saneamento e aporte de demais serviços públicos, como coleta de lixo, luz e água encanada. Entretanto, por meio de um processo estrategicamente segregacionista nas composições das cidades e nos processos de urbanização, essa não é uma realidade acessível a milhões de brasileiros que ainda veem usurpado seu direito à habitação. A reintegração de posse do Pinheirinho, em São José dos Campos, é emblemática nesse sentido, quando, por uma decisão judicial, 1600 famílias viram-se totalmente desalojadas, suas casas demolidas e se viram sem uma perspectiva clara de futuro. A fim de se estudar esse caso importante, desenvolveu-se um levantamento bibliográfico em livros e nas plataformas online e para a descrição do caso utilizou-se a técnica de explanation building. Os resultados serviram para corroborar o mote inicial da pesquisa: a cidade é composta por interesses contrastantes, onde o que vale é o capital, o poder e a dominância.

Palavras-chave: Direito à cidade. Pinheirinho. Reintegração de posse. Planejamento urbano.

\section{Abstract}

Housing is one of the most basic needs of citizens. It is not possible to aim for a better quality of life, to promote a range of other basic rights without the fully in possession of a suitable home, with sanitation and other public services such as garbage collection, light and piped water. However, through a strategically segregationist process in the composition of cities and in the processes of urbanization, this is not an accessible reality to millions of Brazilians who still see usurped their right to housing. The repossession of Pinheirinho in São José dos Campos is emblematic in this sense when, by a judicial decision, 1,600 families were totally dislodged, their houses demolished and threw without a clear perspective of the future. A bibliographic survey was developed in books and online platforms to study this sibylline case and the explanation building technique was used for the description of the case. The results corroborated the 
initial motto of the research: the city is composed of a confluence of contrasting interests, where capital, power and dominance are what counts.

Keywords: Right to the city. Pinheirinho. Repossession. Urban planning.

\section{Introdução}

A urbanização brasileira é um fenômeno epidêmico em todas as regiões do país e que modifica sensivelmente as relações sociais, econômicas e de poder existentes em todo o contexto da realidade local que a circunda.

Santos (2013) descreve que, iniciado no período do Brasil colonial, os índices de urbanização até o século XX eram pouco expressivos, denotando inclusive um processo pretérito de criação urbana. As maiores cidades do país, Recife, Salvador, Rio de Janeiro e São Paulo, juntas não ultrapassavam 2,85 milhões de habitantes em 1872, portanto menos de $6 \%$ de toda a população brasileira.

Do final do século XIX até 1920, tal índice atingiu 10,7\%. Contudo, foram necessárias duas décadas, de 1920 a 1940, para que essas cifras chegassem a $31,24 \%$.

Esse processo, conforme explicam Nobre \& Ramos (2011), só pôde ser consumado a partir da grande industrialização promovida pelos governos de Getúlio Vargas (1930-1945 e 1950-1954) e pelo impulso dado à indústria automobilística no governo de Juscelino Kubitschek (1956-1961). A urbanização mostra-se hoje um processo irreversível, englobando a maior parte dos agentes sociais e econômicos do país.

Maricato (2002) explana que esse processo de industrialização maciça ocorrida a partir da década de 1930 é também resultado de uma modificação de atuação estatal, que passa a privilegiar investimentos em infraestrutura para desenvolvimento industrial visando uma substituição de importações e da ação de uma burguesia que passa a se apossar da hegemonia política do país, sem que houvesse necessariamente uma ruptura com os interesses predominantes estabelecidos.

Singer (2002, p. 30) relata brevemente a aglomeração espacial resultante da industrialização, bem como o motivo pelo qual diversas cidades deram a se desenvolver em seus entornos:

A aglomeração espacial da atividade industrial se deve à necessidade de utilização de uma mesma infraestrutura de serviços especializados (de energia, água, esgotos, transporte, comunicações, etc.) e às economias externas que decorrem da complementaridade entre os estabelecimentos industriais. Para reduzir os custos de transporte que consubstanciam estas economias externas, as empresas que realizam intenso intercâmbio de mercadorias tendem a se localizar próximas umas das outras. Surge daí a cidade industrial. Uma vez a industrialização de um sítio urbano, ele tende a atrair populações de áreas próximas. 0 crescimento demográfico da cidade torna-a, por sua vez, um mercado cada vez mais importante para bens e serviços de consumo, o que passa a constituir um fator adicional de atração de povos, dadas as atividades produtivas [...].

A série histórica do Instituto Brasileiro de Geografia de Pesquisa (IBGE, 2017a) confere essa constatação de que o avanço da taxa de urbanização ocorre nos períodos de maior industrialização do país, havendo praticamente adicionado $10 \%$ ao seu percentual por década durante o século XX.

Entretanto, ainda que a cidade tenha se tornado um grande reflexo do social, concatenando diferentes etnias, credos e culturas, não se pode dizer que todos tenham desenvolvido sentido de pertencimento e sido de modo pleno incluídos nos circuitos sociais, especialmente no que tange à habitação e encontro de oportunidades. A cidade mostra-se um organismo segregacionista e difusor de disparidades que criam uma forte relação de submissão e dependência entre periferia-centro.

Santos (2013, p. 10) relata esse processo excludente:

A cidade em si, como relação social e como materialidade, torna-se criadora de pobreza, tanto pelo modelo socioeconômico, de que é o suporte, como por sua estrutura física, que faz dos habitantes 
das periferias (e dos cortiços) pessoas ainda mais pobres. A pobreza não é apenas o fato do modelo socioeconômico vigente, mas também do modelo espacial.

E tais afirmações encontram simetria de ideias com Singer (1982), de que o acesso a serviços urbanos tende a privilegiar determinadas classes e localidades. Grupos mais ricos concentram-se em áreas diferentes daquelas em que se encontram grupos mais pobres e são justamente as classes mais abastadas que se veem menos servidas de aparato público, serviços essenciais e, por causa disso, de sentido de pertencimento à cidade.

Tomando-se em vista a pertinência do tema, o presente trabalho volta seus olhos a um estudo de caso que torne possível uma demonstração dos conflitos de classes presentes na cidade, evidenciando de que forma o direito à propriedade tem mais valor do que a função social da terra e como o direito à cidade é gestado de acordo com os interesses do capital ${ }^{1}$.

0 estudo de caso analisado será o do Pinheirinho e sua reintegração de posse ocorrida em 2012, na cidade de São José dos Campos.

\section{Planejamento urbano e periferização urbana}

O processo de urbanização intensifica-se, conforme já visto, com o advento da industrialização. Santos \& Silveira (2003) explanam que, ainda que com quase dois séculos de atraso com relação à Europa, que havia iniciado seu desenvolvimento industrial em 1750, no Brasil a industrialização serviu como um verdadeiro ponto de mudança para o que se tinha até então de planejamento social e de prioridades de desenvolvimento, sendo essas predominantemente prioridades voltadas ao mercado e ao capital.

Rolnik (2006) concorda com a concepção de que o epicentro de toda a urbanização é o movimento de industrialização e descreve que, no caso brasileiro, a sensível expansão urbana ocorrida entre 1940-1980 foi decorrente de uma forte migração de um contingente de pobres, sob a premissa de um modelo supostamente desenvolvimentista. Entretanto, tal modelo, respondendo a uma série de interesses da burguesia empresarial daquele momento, serviu apenas para privar a população de baixa renda das condições mínimas de urbanidade (sanitárias e habitacionais), aliviar as tensões do campo e formar mão de obra barata para a indústria. Além disso, mostrou-se ser um processo bastante centralizador, aglomerando $60 \%$ da população urbana em pouco mais de 200 municípios com mais de 100 mil habitantes.

Maricato (2002) expõe que, mesmo com os esforços do Banco Nacional da Habitação (BNH) e do Sistema Financeiro de Habitação (SFH) e com os crescimentos de produto médio superiores a $7 \%$ a.a. durante o período de 1940-1980, os resultados não foram suficientes para influir em melhoras nas condições habitacionais para a população, ao contrário, o financiamento imobiliário não impulsionou a democratização do acesso à terra e a atividade produtiva não conseguiu subjugar as atividades especulativas, mas sim serviram para acentuar as disparidades (já latentes naquele período).

Lefebvre (2001) sintetiza a ideia de valoração do local da cidade com base naquilo que pode oferecer como valor de uso, isto é, da utilização marginal do espaço para o maior retorno ou ganho por parte do acumulador.

A cidade e a realidade urbana dependem do valor de uso. 0 valor de troca e a generalização da mercadoria pela industrialização tendem a destruir, ao subordiná-las a si, a cidade e a realidade urbana, refúgios do valor de uso, embriões de uma virtual predominância e de uma revalorização do uso. No sistema urbano que procuram analisar se exerce a ação desses conflitos específicos: entre valor de uso e valor de troca, entre a mobilização da riqueza (em dinheiro, em papel) e o investimento improdutivo na cidade, entre a acumulação do capital e sua dilapidação nas festas,

\footnotetext{
${ }^{1}$ Descrevem Mastrodi \& Zaccara (2016, p. 865) que “[...] o direito à moradia tem sido assegurado apenas quando da garantia e preservação do direito à propriedade, pois é o que confere ao titular potencial para proteger a coisa contra quem quer que seja. [...] Não há segurança jurídica da posse ou da moradia de modo desvinculado do direito à propriedade."
} 
entre a extensão do território dominado e as exigências de uma organização severa desse território em torno da cidade dominadora. Esta última se protege contra qualquer eventualidade através da organização corporativa que paralisa as iniciativas do capitalismo bancário comercial (Lefebvre, 2001, p. 14).

A constituição das cidades pauta-se em conflitos de interesses e em relações entre dominados e dominadores. As classes que formam a cidade estão em constante desacordo e se contrapondo. É essa máxima de coexistência de conflitos e de dominação que reforça a teoria apresentada por Lefebvre (2001), Abramo (2007) e Santos et al. (2017), que consideram que a segregação espacial e o ordenamento urbano são eventos estratégicos, que desejam separar as cidades, criando agrupamentos socioespaciais, em que as classes mais altas dispõem dos melhores locais.

Não parece ser de difícil conclusão: os mais ricos terão à disposição locais de destaque na mancha urbana, em posições privilegiadas e próximas aos locais de acúmulo de capital, ao passo que aqueles com menor renda e marginalizados, terão de se distanciar dos grandes centros de decisão, dos pontos de concentração de poder, sendo esta uma das facetas da marginalização.

Ribeiro (2007), ao tratar da marginalização, descreve que a dinâmica da cidade brasileira tem como base a apropriação privada de várias formas de renda urbana, resultando em um maior aproveitamento dos aparatos públicos e privados daqueles grupos mais privilegiados, promovendo-lhes bem-estar social e acúmulo de riqueza por meio de patrimônio imobiliário. Aos trabalhadores e demais classes mais baixas, restam os espólios e o não reconhecimento social de suas carências e necessidades de consumo, resultando em uma urbanização sem cidades.

Castells (1983) parte da ótica de marginalização através da perda de significação de papéis, não só econômicos, na qual os trabalhadores são apenas parte secundária da cadeia produtiva, mas também sociais para sinalizar que o processo impõe substancial submissão e dependência entre as classes existentes na cidade e sociedade.

Uma sociedade é dependente, quando a articulação de sua estrutura social, em nível econômico, político e ideológico, exprime relações assimétricas com outra formação social que ocupa, frente à primeira, uma situação de poder. Por situação de poder, entendemos o ato de que a organização das relações de classe na sociedade dependente exprime a forma de supremacia social adotada pela classe no poder na sociedade dominante (Castells, 1983, p. 82).

Lefebvre (2001, p. 25) discorre sobre esse processo de periferização salientando um dos resultados desse processo, a alienação:

Com a "suburbanização" principia um processo que descentraliza a Cidade. Afastado da Cidade, o proletariado acabará de perder o sentido da obra. Afastado dos locais de produção, disponível para empresas esparsas a partir de um setor de habitat, o proletariado deixará se esfumar em sua consciência a capacidade criadora. A consciência urbana vai se dissipar. [...] Em redor da cidade instala-se uma periferia desurbanizada e, no entanto dependente da cidade. Com efeito, os "suburbanos", os dos "pavilhões" residenciais, não deixam de ser urbanos mesmo que percam a consciência disso e se acreditem próximos da natureza, do sol e do verde. Urbanização desurbanizante e desurbanizada, pode-se dizer para ressaltar o paradoxo.

Sobre isso, Villaça (2001) trata de que esses centros possuem extrema relevância onde estão inseridos. São locais de onde emanam as decisões sociopolítico culturais acerca da cidade, concentram alto grau de serviços urbanos e concentram as zonas residenciais das populações mais ricas, com sobrevalorização gradiente do solo urbano local, ao passo que a periferia se define pela sua condição de dependência do centro, em um espaço de exclusão, de marginalidade social e cidadania incompleta.

E pela relevância destes centros e por abrigarem as classes mais abastadas, é que se tenta que ocorra o afastamento das populações mais carentes e sua alienação de pertencimento ao meio. É essa visão desigual e alienadora que, na concepção de Godard \& Castells (1979) deve ser combatida pelo planejamento urbano, uma vez que esse é um instrumento de mediação e negociação entre as classes dominante e dominada, bem como meio de reinvindicação. 
Em $O$ Estado capitalista e a questão urbana, ao fazer um paralelo sobre a alienação resultante da desigualdade espacial, Lojkine (1997) discorre que a mais forte das segregações sociais jaz na localização da habitação e que, acoplado a essa, surgem outras tão críticas quanto, sendo as mais notáveis:

1. Subequipamento dos conjuntos coletivos, como creches, escolas, postos médicos e locais de lazer;

2. Subequipamento dos transportes, havendo maiores complicações para que os periféricos possam deixar seus locais de habitação;

3. Subequipamento dos serviços básicos, como tratamento de esgoto e coleta de lixo.

Os dados do IBGE conferem robustez às afirmações de Lojkine (1997). Nota-se, pelos dados publicados em Síntese dos indicadores sociais (IBGE, 2016), que ainda há um enorme desnivelamento no acesso dos aparatos listados nos três subtópicos levantados. De acordo com essa mesma obra:

- Ainda há $12 \%$ da população brasileira que não possui nenhum tipo de atendimento de coleta de lixo. Para os negros esse número aumenta para 16\%;

- Apenas 65,3\% dos brasileiros possuem coleta de esgoto, sendo que nos locais onde há predominância branca esse racional salta para $74 \%$ e cai para $57,9 \%$ onde há maior predominância negra entre a população.

Nos estudos de déficit habitacional, o déficit brasileiro atingiu, no ano de 2015, o montante de 6.186.503 milhões de domicílios, com maior número absoluto em São Paulo (1.3 milhão) e maior índice relativo na região Norte $(12,6 \%)$ (FJP, 2017).

Ainda assim, muito mais do que a questão numérica, a qualitativa tem seu severo impacto na questão habitacional, sendo essa merecedora de grande apreço para entendimento.

Ribeiro (2007) critica que os números sobre melhoria das condições habitacionais, que são frequentemente divulgados, pouco revelam os dramas reais das cidades, inaptas à função de sustentação de uma vida digna, nas quais vivem pessoas expostas a condições insalubres.

Maricato (2002) faz um paralelo em seus estudos: há duas cidades, uma chamada de "cidade legal", que corresponde aos loteamentos regularizados e devidamente atendidos pelo poder público e a "cidade real", que é constituída pelas ocupações irregulares, favelas, e que é seguidamente marginalizada. Nesses locais a cidadania é para poucos e os direitos não universais. A autora complementa que ainda que o direito à invasão e ocupação sejam assegurados, o direito à cidade, isto é, ao uso racional de seus aparatos, não.

Maricato \& Santos (2007) caracterizam que o que há na verdade é a negação ao direito à cidade expresso na irregularidade fundiária, no déficit habitacional e na habitação inadequada. Os autores apontam que, ao passo que as camadas mais baixas não têm acesso aos aparatos públicos, os mais ricos continuam acumulando e ostentando luxos exagerados. Nesse cenário, o urbanismo demonstra sua limitação e ineficácia para lidar com os problemas contemporâneos das cidades.

E, de fato, a competência do Estado como propiciador de bem-estar parece ser bastante contestada. Rolnik (2006) salienta que as benfeitorias respondem a interesses poucos e por vezes escusos. Para ela, é notório que a política habitacional, o planejamento e a gestão do solo mais contribuem para a exclusão territorial do que auxiliam em sua mitigação, uma vez que esses locais sofrem apenas microinvestimentos em infraestrutura e normalmente estão condicionados à promoção do clientelismo nas regiões metropolitanas.

E a suposta obrigação de perseguição de condições racionais de formas de uso e ocupação de solo pelo Estado, de maneira a promover bem-estar à população, poderia ser alcançada através de todo o planejamento urbanístico e de seus instrumentos.

Maricato (2007) disserta que as condições impostas pela quase total ausência do Estado configuram uma "não cidade", em que se cede espaço a novas leis, muitas vezes impostas por "chefes locais". A autora destaca algumas das propostas para mitigação desses percalços: I) dar visibilidade à cidade real ou desconstruir a cidade virtual edificada pelo marketing urbano e interesses globais; II) Criar um espaço de debate democrático: dar visibilidade aos conflitos; III) Realizar reforma administrativa que leve a presença do Estado aos bairros irregulares e faça redistribuição de atributos operacionais; IV) Promover capacitação de agentes para o planejamento da ação e reforma fundiária. 
Esses pontos são notáveis e serão discutidos a seguir, igualmente, mais uma vez, convém voltar ao fato de que as ações na cidade respondem a interesses específicos. Com a dificuldade de obtenção de terras/propriedade nos centros e consequente periferização, mesmo uma ação aparentemente boa, como a realização de obras de infraestrutura, pode estar carregada de proveitos financeiros destinados a poucos.

Sobre isso, Santos (2013) elucida que os aportes de infraestrutura efetuam também uma ação próespeculação, uma vez que valorizam os terrenos ao redor destas obras e geram uma espiral de utilização do aparato público em serviço do rentismo.

Os conjuntos residenciais, levantados com dinheiro público - mas por firmas privadas - para as classes médias baixas e os pobres, situam-se quase invariavelmente nas periferias urbanas, a pretexto dos preços mais acessíveis dos terrenos, levando, quando havia pressões, a extensões de serviços públicos como luz, água, às vezes esgotos, pavimentação e transportes, custeados, também com os mesmos recursos. [...] A construção de um conjunto residencial e a consecutiva dotação de infraestruturas valoriza os terrenos ao derredor, estimulando os proprietários a uma espera especulativa. Produzem-se novos vazios urbanos, ao passo que a população necessitada de habitação, mas sem poder pagar pelo seu preço nas áreas mais equipadas, deve deslocar-se para mais longe, ampliando o processo de periferização (Santos, 2013, p. 124).

Maricato (2002) relata que é normal que o poder público se torne omisso aos vazios urbanos resultantes de suas próprias ações, pois são também responsáveis pela enorme valorização financeira resultante do novo aparato urbano presente. A consequência inevitável é que as populações de mais baixa renda continuem a serem movidas para áreas cada vez mais periféricas, afastadas de um desenvolvimento urbano racional e includente e em muitos casos em condições irregulares de habitação e de parcelamento do solo.

Trindade (2014) elucida que esse processo de maior centralização das populações abastadas, promovendo a elevação dos valores imobiliários locais é denominado de gentrificação e seus principais resultados são a modificação da composição social local, com a expulsão das camadas de estratos mais baixos de seus locais de origem.

Aos poucos, uma conclusão básica começa a se formar: a cidade, ainda que englobe muitos indivíduos, como um grande conjunto de munícipes, acaba por ser para poucos. As classes dominadas vivem em constante relação de dependência dos grandes centros, além de ficarem alienadas dos processos decisórios. Na luta entre interesses de dominados e dominadores, o que há é uma constante segregação, que de nada contribui para a formação de um todo com sinergia e justiça.

A Constituição Federal de 1988 serviu para sacramentar, em seu art.5ํ, incisos XXII e XXIII, o direito à propriedade e a sua função social (Brasil, 2018).

Muniz \& Silva (2017) dissertam que outra prerrogativa importante predisposta na CF de 1988 é a do conjunto de dispositivos jurídicos, urbanísticos, ambientais e sociais que asseguram o desenvolvimento das funções sociais da propriedade. Dessa forma, a nova Constituição, com seus novos artífices, propiciou um redimensionamento do Estado e de seus institutos jurídicos sobre a propriedade (nota: propriedade e não o direito à moradia) e na delimitação de futuras políticas públicas que viessem a se assentar.

Os artigos 182 e 186 da citada Constituição também se mostram de extrema importância para o planejamento urbano, pois sistematizam respectivamente a consonância da política de desenvolvimento urbano - em âmbito municipal - com o ordenamento de pleno desenvolvimento das funções sociais da propriedade e quais os critérios que serão considerados para o enquadramento de uma propriedade sobre cumprimento ou não de sua função social (Brasil, 2018).

Um dos principais avanços para tentar fortalecer o tratamento do planejamento, visando sanar possíveis distorções sociais, foi a promulgação do Estatuto das Cidades (EC), lei 10.257/01, que veio, inclusive, regulamentar os artigos 182 e 183 da Constituição Federal.

De acordo com Boeira et al. (2009, p. 702), configura-se o EC como um instrumento legal que almeja uma melhor ordenação do espaço urbano, bem como uma via para reduzir os problemas sociais graves. 
O EC é um instrumento legal que visa combinar a gestão participava com as premissas da sustentabilidade ecológica e econômica, além de introduzir um novo conceito de gestão urbana, objetivando a melhor ordenação do espaço-urbano com observância da proteção ambiental e a busca de solução para problemas sociais graves, como a moradia e o saneamento, por exemplo, que o caos urbano faz incidir, de modo contundente, sobre as camadas carentes da sociedade.

O EC, da forma com que está escrito, prevê uma gestão participativa, isto é, englobando os grupos constituintes das cidades, para que contribuam e pensem a cidade a qual desejam, bem como oferece uma série de garantias e preocupações que seguramente são legítimas no que alude às distorções citadas neste trabalho. Em seu artigo $2^{\circ}$, cujo caput explicita os objetivos da política urbana, seu inciso VI aborda claramente que as ordenações de solo devem evitar a retenção especulativa do imóvel urbano que resulte em sua subutilização e a utilização inadequada de imóveis urbanos (Brasil, 2001).

Mais à frente, nos capítulos 3 e 4, o EC dispõe sobre as prerrogativas que são de competência da União, em conjunto com estados e municípios, a promoção de programas de habitação, com construção e melhoria adjacentes à habitação, como saneamento básico, diretrizes de transporte e mobilidade urbana, que permitam acessibilidade aos locais públicos. Como instrumentos principais serão utilizados:

- Planos nacionais, regionais e estaduais de ordenação de território;

- Planejamento de regiões metropolitanas e microrregiões;

- Planejamento municipal, em especial valendo-se do Plano Diretor, que é o instrumento básico de orientação municipal (Brasil, 2001).

Alguns outros importantes instrumentos constantes no Estatuto das Cidades são: o parcelamento, edificação ou utilização compulsórios; a usucapião de imóvel urbano singular ou coletivo, a concessão de uso especial para fins de moradias, o direito de superfície, o direito de preempção, a outorga onerosa do direito de construir, as operações urbanas consorciadas, a transferência do direito de construir, o estudo de impacto de vizinhança e a gestão democrática da cidade (Brasil, 2001).

A questão da regulação fundiária, de fundamental importância para se legalizar a permanência de indivíduos em áreas urbanas em desacordo com a legislação pátria, está disposta na atual Lei n. 13.465/2017, uma modificação da antiga Lei n. 11.977/2009, e, portanto, fora das disposições do Estatuto das Cidades.

Inicialmente, a lei em vigência era a Lei n. 11.977/2009, que buscava unicamente o desenvolvimento das funções sociais da propriedade e hoje, após a modificação, objetiva garantir ao indivíduo o direito à posse de uma moradia digna e integração dos assentamentos informais ao conjunto da cidade, quebrando esse ciclo vicioso de exclusão e não pertencimento da cidade (Rocha \& Silveira, 2017).

Com base no previamente exposto, é possível indagar se o Estado, enquanto promotor e garantidor desses direitos, tem sido ineficaz tanto em atingir suas responsabilidades para com a asseguração de habitação, tanto quanto para coibir que o rentismo e a especulação imobiliária ocorram sob sua tutela.

Para melhor contextualizar as discussões, o presente artigo se voltará nesse momento para o estudo de caso do Pinheirinho, uma comunidade de São José dos Campos que sofreu reintegração de posse no ano de 2012.

\section{Do direito fundamental à moradia à reintegração de posse}

São José dos Campos mostra ser uma cidade muito bem abastecida de recursos. O IBGE (2017b) demonstra que o Índice de Desenvolvimento Humano do município é de 0,807, portanto um dos mais altos do Estado de São Paulo e que seu orçamento aproxima-se de 2 bilhões de reais. Além de contar com mais de 90 estabelecimentos de saúde, para uma população próxima de 630 mil habitantes, com PIB per capita de $45.411,77$ reais ao ano. 
Essas descrições não condizem, entretanto, com a situação dual e dicotômica que se viveu em São José dos Campos com o Pinheirinho.

Montenegro (2017) relata que a ocupação do Pinheirinho deu-se em 2004, em um terreno de 1,3 milhão de metros quadrados pertencente à massa falida da Selecta S.A, empresa do megaempresário e especulador Naji Nahas. Localizada em um distrito industrial, com $45 \%$ de sua área total obrigatoriamente destinada à preservação ambiental, esse imenso terreno já se encontrava em desuso há mais de 15 anos. Não havendo nenhuma função ali que não o simples existir, a área passou a ser ocupada por 1600 famílias.

Forlin \& Costa (2010) descrevem que as condições de habitação eram precárias: os barracos eram construídos com madeiras e lona, cuja responsabilização de construção era dos próprios habitantes. As divisões de terrenos eram feitas com arames em pequenos lotes de $10 \mathrm{~m}$ de largura e $25 \mathrm{~m}$ de comprimento. Ligações clandestinas de luz eram presentes em toda a ocupação. A água para banho e preparação dos alimentos era obtida de uma nascente próxima e coletada com baldes. Banheiros normalmente eram nos quintais. Havia plantações para subsistência, bem como uma incipiência de comércio (25 microestabelecimentos na época de seu estudo).

Teixeira (2016), em sua tese "A atuação do poder judiciário nos conflitos de terra: o caso do Pinheirinho", realizou uma série de entrevistas com moradores e dirigentes do Pinheirinho e descobriu maiores informações sobre as formas com que se estruturava a ocupação: a) As decisões eram tomadas em assembleias gerais, realizadas aos sábados; b) A estrutura métrica empregada nos terrenos $(25 \mathrm{~m} \times 10 \mathrm{~m}$ com recuo de $5 \mathrm{~m})$ era estrategicamente feita para que se houvesse o arruamento, com avenidas, praças e delimitação de espaço coletivo; c) Havia um estrito código de ordem e limpeza gerais que imperavam sobre o Pinheirinho, seus cidadãos tinham a obrigação de zelar pela limpeza das vias, dos lotes, além de garantirem assiduidade das crianças nas escolas. Imperava uma exacerbada solidariedade entre os integrantes do Pinheirinho, trabalhando conjuntamente para sanarem problemas pontuais de seus participantes, como fome.

Ainda que não da melhor maneira possível, mas, para muitos, aquela era a primeira vez que faziam valer as questões relativas à moradia, previstas no artigo $6^{\circ}$. da Constituição Federal, que prevê que "[...] são direitos sociais a educação, a saúde, a alimentação, o trabalho, a moradia, o transporte, o lazer, a segurança, [...] na forma desta Constituição" (Brasil, 1988).

As condições propiciadas pela ocupação do Pinheirinho também encontravam lastro no Plano Diretor do Município em vigência, Lei Complementar 121/95:

Nos seus artigos 3 e 64, que tratam respectivamente das diretrizes gerais do Plano Diretor e das diretrizes específicas da habitação lê-se que:

"Art. 3ำ A consecução dos objetivos gerais do Plano Diretor dar-se-á com base nas seguintes diretrizes gerais para o desenvolvimento físico, econômico e social do Município: [...]

VI - Reconhecimento do papel do Poder Público Municipal no provimento dos bens e serviços essenciais à vida digna, consignados com direitos de todos e adequados às características socioeconômicas da população.;

$[\cdots]$

VIII - Acesso a um lugar social digno, tanto do ponto de vista da moradia como do trabalho, que assegure uma vida física e mental sadia.

$[\cdots]$

X - Cumprimento da função social da propriedade, prevalecendo sobre o exercício do direito de propriedade individual ou coletivo.

$[\cdots]$

Art. 64. A política municipal de habitação observará as seguintes diretrizes: 
I - Viabilizar o acesso ao solo urbano, especialmente à população de baixa renda (São José dos Campos, 1995).

Se Pinheirinho ajudaria uma série de promoções de direitos básicos dos cidadãos, dependendo apenas de um Estado que interviesse em seu auxílio, expropriasse as terras e promovesse o melhoramento das condições básicas de estrutura e serviço daquele local, por qual motivo a ocupação sofreu uma reintegração de posse? Qual a utilidade daquele terreno a um megaempresário, sendo que era apenas uma massa falida desde 1991, cuja prefeitura era uma de suas maiores credoras?

A resposta parece jazer no interesse financeiro. Souza et al. (2016) revelam que o valor do terreno era avaliado em 187,9 milhões de reais.

Forlin \& Costa (2010), na ocasião da escrita de seu artigo, dois anos antes da reintegração de posse, já alertavam para as mais diversas investidas de Nahas, auxiliado pelo aparato público para colocar a ocupação em xeque, haja vista que, por mais de duas vezes, a Polícia Militar de São José havia tentado reaver a posse do terreno, respaldada por liminares expedidas pela $1^{\underline{a}}$ Vara, que pedia a derrubada dos barracos ali. Ambas as medidas foram derrubadas judicialmente por agravo de instrumento.

Em 2005, a prefeitura havia conseguido judicialmente suspender os serviços de água e eletricidade, que eram clandestinos. Essa liminar foi derrubada por uma medida cautelar, que alegava que já estavam em negociação com a Sabesp e com a Bandeirante Energia pedidos de regularização da situação. Além disso, a prefeitura deliberadamente não punha à serviço da ocupação seu aparato de Defesa Civil quando ocorriam quedas de barrancos e tampouco disponibilizava vagas em creches e atendimentos em hospitais para as pessoas do Pinheirinho. (Forlin \& Costa, 2010).

A área que já não cumpria sua função social há anos e que possuía dívidas que excediam o valor venal do terreno jamais poderia ter sofrido tais ataques. 0 próprio EC fornecia bases legais para que o terreno fosse desapropriado para habitação popular, através do instrumento da "adjudicação", isto é, a posse do terreno pela prefeitura em troca da dívida.

Todas essas investidas contra a população e em favor do capital reforçam a ideia de que a cidade é para poucos e de que há uma incrível leniência das esferas públicas para com o capital. Santos (2013, p. 123) aponta esse mesmo problema em $A$ urbanização brasileira:

0 próprio poder público torna-se criador privilegiado de escassez, estimula, assim, a especulação e fomenta a produção de espaços vazios dentro das cidades; [...] 0 poder público, entretanto, não age apenas de forma indireta. Ele também atua de forma direta na geração dos problemas urbanos, ainda que prometendo resolvê-los.

O judiciário não resolveu o conflito instaurado entre os ocupantes do Pinheirinho e os agentes especuladores imobiliários, uma vez que decidiu pela reintegração de posse do Pinheirinho em 2012. Montenegro (2017) descreve a barbárie que foi esse processo. Viabilizando a retirada dos moradores, foi enviado um verdadeiro arsenal. Eram dois mil policiais armados, cães, viaturas, carros blindados e helicópteros de suporte. Os moradores que resistiram com paus e pedras foram recebidos por balas de borracha, bombas de gás e os demais aparatos já listados anteriormente. A truculência foi tanta que, sob ataque, os habitantes do Pinheirinho não puderam nem ao menos tomar seus documentos para consigo.

De posse de uma contestável liminar, concedida pela justiça estadual de São Paulo, favorável à reintegração de posse, a ação policial despertou manifestações de indignação de diversas organizações, nacionais e internacionais, de direitos humanos que questionam a forma conflituosa como o processo foi conduzido, uma vez que os confrontos com os moradores resultaram em várias pessoas feridas, supostas mortes, além das prisões e toda a situação de horror a que foram submetidas crianças, idosos, homens e mulheres que perderam tudo o que construíram nos últimos oito anos (Montenegro, 2017, p. 2).

E há denúncias de que os direitos humanos dos então moradores do Pinheirinho foram violados e vilipendiados durante a reintegração. Uma reportagem do jornal $O$ Globo relata que treze oficiais da ROTA foram indiciados pela Corregedoria da Polícia Militar (PM) por estupro, agressão e tortura, inclusive com submissão de tratamento de choque e coação moral para tratamentos humilhantes dos 
moradores (O Globo, 2013). Todas as acusações chegaram a ser enviadas ao Conselho de Direitos Humanos da Organização dos Estados Americanos (OEA), porém sem resoluções até hoje.

E não só isso, a desocupação foi um atropelo às normas jurídicas. Andrade (2013) explica que a juíza que autorizou a reintegração não poderia tê-lo feito. 0 pedido, que já havia sido feito em 2005, pela Selecta na $6^{\underline{a}}$ vara civil de São José Campos, foi indeferido. Pouco tempo depois, a $18^{\underline{a}}$ Vara havia acatado e despachado em prol do empresário, contudo o Tribunal de Justiça - SP derrubou a decisão, por entender que não havia competência para a $18^{\mathrm{a}}$ Vara despachar sobre o caso, e o processo voltou para a $6^{\mathrm{a}}$ Vara.

O Sindicato dos Servidores das Justiças Federais (SISEJUFE, 2012), leciona que o problema todo se passou quando, em 2011, a juíza da $6^{\text {a }}$ Vara resolveu acatar a deliberação da 18 ${ }^{\mathbf{a}}$ Vara. Quando alertada de que aquela decisão havia sido derrubada, ela resolveu então retirar o seu despacho, dizendo que era uma revisão da decisão de 2005, e que tal reintegração seria necessária, pois o governo não dava sinais claros de que a União ou quaisquer entender federativos se interessariam pela urbanização do local.

Ao fazê-lo, a juíza ignorou a liminar do Tribunal Regional Federal (TRF) da 3a. Região que explicitava interesse da União pelo local e suas questões de urbanização. Também ignorou os artigos 5, 182 e 170 da Constituição Federal que reconhecem a função social da propriedade e que esta deve atingir o bem-estar da população e o fundamental direito à moradia. Atropelou o Despacho da 1a Vara da Fazenda Pública, do juiz Silvio Pinheiro, que proibia a derrubada das casas e também desatentou-se ao estudo da própria prefeitura encaminhado pela Secretaria de Governo do Município à Companhia de Desenvolvimento Habitacional e Urbano do Estado (CDHU) reforçando pedidos de ajuda para a regularização da área.

Os moradores tão logo foram desalojados, a prefeitura tratou de aprovar a Lei 8.598/12 que instituía a cessão de aluguel social e auxílio mudança aos ex-moradores do Pinheirinho. 0 valor era uma monta meramente simbólica, R\$ 500,00, em que RS 400,00 eram responsabilidade do Governo do estado de São Paulo e o restante da prefeitura. A lei previa que o prazo máximo do recebimento do aluguel social fosse de 12 meses, prorrogáveis caso não se chegasse a uma solução definitiva de moradia aos moradores (São José dos Campos, 2012). Uma peculiaridade desse aluguel é que, ao longo de todo seu tempo de existência (2012-2017), ele não foi reajustado em nenhuma ocasião, o que acarretou perdas reais de poder de compra e aos moradores, em um benefício já insuficiente para sanar todas necessidades básicas.

Em 2014, o Governo Federal anunciou que as famílias do Pinheirinho receberiam o que classificou de "moradias dignas", isto é, 1.724 habitações do Programa Minha Casa, Minha Vida (Brasil, 2018). A Secretaria da Habitação do Estado de São Paulo relatava que além de toda infraestrutura básica como saneamento, esgoto e rede elétrica, a área externa do conjunto habitacional contaria com uma creche, uma Unidade de Pronto-Atendimento (UPA), áreas verdes, lazer e centro comercial (São Paulo, 2018).

As chaves dos Residenciais Pinheirinhos dos Palmares foram entregues aos moradores no dia 22 de dezembro de 2016. Os apartamentos possuíam 46,5 metros quadrados, dois quartos, sala, cozinha, banheiro e área de serviço (São José dos Campos, 2016). 0 bairro onde estão localizadas essas casas, o Emha 2, fica a mais de 20 quilômetros do centro da cidade, é uma área periférica e subequipada.

Contudo, a concepção de que as habitações recebidas são dignas, parece não ser factual ${ }^{2}$. Mastrodi \& Zaccara (2016) lecionam que a política habitacional do Minha Casa, Minha Vida é realizada por agentes do mercado em áreas bastante afastadas da cidade, não integradas ao tecido social, longe de quaisquer elementos de integração social, postas no entorno excluído dos centros de decisões e, para viabilizar tais habitações, o programa ainda incorre em mais uma forma de exclusão: aquela praticada pelas instituições bancárias, que exigem lastros e maiores garantias. A população mais necessitada acaba não sendo por vezes elegível ao crédito imobiliário.

0 caso do Pinheirinho é um exemplo para se tratar das diferenças entre a cidade real e a cidade virtual. Também são notórios os conflitos de interesses e classes que permeiam as relações sociais no urbano. Atropelam-se direitos e a norma jurídica em prol da especulação. Não se respeitam direitos elementares

\footnotetext{
${ }^{2}$ A definição convencional sobre moradia adequada é a do Comitê dos Direitos Econômicos, Sociais e Culturais das Nações Unidas (UNHCHR, 1991), que dispõe sete critérios principais a serem perseguidos: Segurança de posse; Disponibilidade de serviços, materiais, instalações e infraestrutura; Economicidade; Habitabilidade; Acessibilidade; Localização e Adequação Cultural.
} 
como o da Moradia e dignidade humana, estipulam a tortura e pancadas para tratar com pessoas. O conceito de não cidade, apontado no texto, torna-se a Lei em que o Estado é omisso.

Uma vez desapropriada a terra nota-se o interesse que o poder público poderia ter na desocupação. Com a retirada dos habitantes do Pinheirinho, o terreno pôde ser vendido e seu crédito com a Prefeitura, pago. Além do lucro residual do empresário ter sido garantido. Contudo deve-se sempre ter o zelo de indagar: a custo de que ou de quem?

\section{Considerações finais}

Pinheirinho é uma prova de que a teoria que relaciona os estados de dependência entre centroperiferia e de que a segregação espacial nas cidades são, antes de qualquer coisa, parte da estratégia que rege o funcionamento urbano.

A urbanização como necessidade para atingir melhores condições de vida para a população e, também, de forma mais ampla, como reflexo de desenvolvimento, afasta-se da realidade do social, privilegiando os interesses do capital em detrimento de prerrogativas básicas, como a função social ou direito à cidade, como apresentado no caso do Pinheirinho. 0 dominante sistema de economia de mercado rejeita o Estado dentro de sua dinâmica criacionista, mas recorre a ele para a manutenção da sua obra.

Englobando boa parte da população brasileira, é notório que há diversas cidades dentro de uma mesma e que cada uma atende aos respectivos interesses de sua própria classe e população. Mas que no final a cidade, enquanto organismo vivo, responde aos anseios de um pequeno grupo dotado ora de poder financeiro ora de influência, ou os dois, conjuntamente, para assegurar que haja todo um aparato de Estado que o auxilie na eminência de algum conflito que fira o status quo.

No caso do Pinheirinho, o Estado teve uma postura ambígua, ora favorecendo os então moradores, ora favorecendo o capital, porém, no final, manteve sua histórica postura contingencial e beneficiou a parte mais próxima do topo da pirâmide social. 0 estudo demonstrou que o Estado planeja apenas de acordo com o que lhe convém e, sendo a mais poderosa força balizadora de interesses, acaba por alavancar distorções sociais, produzir vazios, propiciar a especulação, gerando disparidades.

\section{Referências}

Abramo, P. (2007). A cidade caleidoscópica: coordenação espacial e convenção urbana: uma perspectiva para a economia urbana. Rio de Janeiro: Bertrand Brasil.

Andrade, I. D. (2013). A gente já nasce lutando: a desocupação do Pinheirinho, a política entre o formal e o informal. Revista de Antropologia, 56(1), 45-80.

Boeira, S. L., Santos, A. C. B., \& Santos, A. G. (2009). Estatuto da Cidade: aspectos epistemológicos, sociopolíticos e jurídicos. Revista de Administração Pública, 43(3), 695-712. http://dx.doi.org/10.1590/S003476122009000300008.

Brasil. (1988, 5 de outubro). Constituição da República Federativa do Brasil de 1988. Brasília: Diário Oficial da União. Recuperado em 11 novembro de 2017, de http://www.planalto.gov.br/ccivil_03/constituicao/constituicao.htm

Brasil. (2001, 11 de setembro). Lei n. 10.257, de 10 de julho de 2001. Regulamenta os arts. 182 e 183 da Constituição Federal, estabelece diretrizes gerais da política urbana e dá outras providências. Brasília: Diário Oficial da União. Recuperado em 11 novembro de 2017, de http://www.planalto.gov.br/ccivil_03/leis/LEIS_2001/L10257.htm

Brasil. Ministério do Planejamento, Desenvolvimento e Gestão. Programa de Aceleração do Crescimento - PAC. (2018). Famílias do Pinheirinho (SP) ganharão residência definitiva com toda estrutura social. Brasília. Recuperado em 7 de maio de 2018, de http://www.pac.gov.br/noticia/2bab4ef4

Castells, M. (1983). A questão urbana (A. Caetano, Trad.). Rio de Janeiro: Paz e Terra. 
Forlin, L. G., \& Costa, S. M. F. (2010). Urbanização e segregação sócio-espacial na cidade de São José dos Campos: o caso Pinheirinho. GEOSUL, 25(49), 123-158. http://dx.doi.org/10.5007/2177-5230.2010v25n49p123.

Fundação João Pinheiro - FJP. (2017). Déficit habitacional no Brasil 2015. Belo Horizonte: FJP. Recuperado em 11 de novembro de 2017, de http://www.fjp.mg.gov.br/index.php/docman/cei/723-estatisticas-informacoes-3deficit-habitacional-16-08-2017versao-site/file

Godard, F., \& Castells, M. (1979). 0 advento de Monopolville: análise das relações entre a empresa, o Estado e o urbano. In R. Forti (Ed.), Marxismo e urbanismo capitalista textos críticos (Vol. 1, pp. 93-117). São Paulo: Ciências Humanas.

Instituto Brasileiro de Geografia e Estatística - IBGE. (2016). Síntese de indicadores sociais (pp. 97-112). Rio de Janeiro: IBGE. Recuperado em 11 de novembro de 2017, de https://www.ibge.gov.br/estatisticasnovoportal/sociais/habitacao/9221-sintese-de-indicadores-sociais.html?\&t=publicacoes

Instituto Brasileiro de Geografia e Estatística - IBGE. (2017a). Censo demográfico 1940-2010. Rio de Janeiro: IBGE. Recuperado em 8 de novembro de 2017, de https://seriesestatisticas.ibge.gov.br/series.aspx?no=10\&op=0\&vcodigo=POP122\&t=taxa-urbanizacao

Instituto Brasileiro de Geografia e Estatística - IBGE. (2017b). São José dos Campos. Rio de Janeiro: IBGE. Recuperado em 11 de novembro de 2017, de https://cidades.ibge.gov.br/xtras/temas.php?codmun=354990\&idtema=16

Lefebvre, H. (2001). O direito à cidade (5. ed.). São Paulo: Centauro.

Lojkine, J. (1997). O Estado capitalista e a questão urbana. São Paulo: Martins Fontes.

Maricato, E. (2002). Brasil, cidades: alternativas para a crise urbana. Rio de Janeiro: Vozes.

Maricato, E. (2007).Globalização e política urbana na periferia do capitalismo. In L. C. Q. Ribeiro, \& O. A. Santos, Jr. (Eds.), As metrópoles e a questão social brasileira (1. ed., Vol. 1, pp. 51-76). Rio de Janeiro: Revan.

Maricato, E., \& Santos, O. A., Jr. (2007). Construindo a política urbana: participação democrática e o direito à cidade. In L. C. Q. Ribeiro, \& O. A. Santos, Jr. (Eds.), As metrópoles e a questão social brasileira (1. ed., Vol. 1, pp. 165195). Rio de Janeiro: Revan.

Mastrodi, J., \& Zaccara, S. M. L. S. (2016). 0 que é o objeto "moradia" do programa Minha Casa, Minha vida? Revista de Direito da Cidade, 8(3), 856-885.

Montenegro, D. M. (2017). Somos Todos Pinheirinho! Violência, exceção e predação como interfaces da barbárie do Estado. Recuperado em 11 de novembro de 2017, de

http://actacientifica.servicioit.cl/biblioteca/gt/GT24/GT24_MorenoMontenegro.pdf

Muniz, M.A.P.C., \& Silva, M.M.P. (2017). Regularização fundiária e direito à moradia. Revista PGM: Procuradoria Geral do Município de Fortaleza, 25(1).

Nobre, P. A. M., \& Ramos, E. M. B. (2011). A cidade e o capital: um breve histórico da situação da classe operária. Brasília: Ipea. Recuperado em 8 de novembro de 2017, de http://www.ipea.gov.br/code2011/chamada2011/pdf/area1/area1-artigo17.pdf

O Globo. (2013, 24 de julho). Indiciados 13 PMs da Rota por abuso sexual e outros crimes em ação paralela ao Pinheirinho. Recuperado em 6 de maio de 2018, de https://oglobo.globo.com/brasil/indiciados-13-pms-da-rotapor-abuso-sexual-outros-crimes-em-acao-paralela-ao-pinheirinho-9169516

Ribeiro, L. C. Q. (2007). Desafios na construção da cidadania na metrópole brasileira. Revista Sociedade e Estado, 22(3), 525-544. http://dx.doi.org/10.1590/S0102-69922007000300003.

Rocha, M. S. M., \& Silveira, R. R. (2017). Da regularização fundiária das ocupações irregulares do solo urbano e a concretização do direito social à moradias. Revista de Direito Urbanística, Cidade e Alteridade, 3(2), $72-87$. http://dx.doi.org/10.26668/IndexLawJournals/2525-989X/2017.v3i2.2625.

Rolnik, R. (2006). A construção de uma política fundiária e de planejamento urbano para o país: avanços e desafios (Políticas Sociais, Acompanhamento e Análise, Vol. 12). Brasília: Ipea. 
Santos, A. P., Polidori, M. C., Peres, O. T., \& Saraiva, M. V. (2017). 0 lugar dos pobres nas cidades: exploração teórica sobre a periferização e pobreza na do espaço-urbano na América Latina. urbe. Revista Brasileira de Gestão Urbana, 9(3), 430-442. http://dx.doi.org/10.1590/2175-3369.009.003.ao04.

Santos, M. (2013). A urbanização brasileira. São Paulo: Universidade de São Paulo.

Santos, M., \& Silveira, M. L. (2003). O Brasil, território e sociedade no início do século XXI. Rio de Janeiro: Record.

São José dos Campos. (1995). Lei complementar n. 121/1995. Institui o Plano Diretor de Desenvolvimento Integrado - PDDI, do município de São José dos Campos para o próximo decênio e dá outras providências. São José dos Campos: Diário Oficial. Recuperado em 11 de novembro de 2018, de https://leismunicipais.com.br/a/sp/s/sao-jose-doscampos/lei-complementar/1995/12/121/lei-complementar-n-121-1995-dispoe-sobre-a-politica-territorial-eurbana-do-municipio-institui-o-plano-diretor-de-desenvolvimento-integrado-da-cidade-de-sao-jose-dos-campose-da-outras-providencias

São José dos Campos. (2012). Lei n. 8.598/12, de 31 de janeiro de 2012. Institui o aluguel social e o auxílio-mudança, autoriza o Poder Executivo a celebrar convênio com o Governo do Estado de São Paulo e dá outras providências. São José dos Campos: Diário Oficial. Recuperado em 1 de maio de 2018, de http://servicos2.sjc.sp.gov.br/legislacao/Leis/2012/8598.pdf

São José dos Campos. (2016). Moradores do Pinheirinho dos Palmares recebem as chaves das casas. São José dos Campos. Recuperado em 5 de maio de 2018, de

http://servicos2.sjc.sp.gov.br/noticias/noticia.aspx?noticia_id=26221

São Paulo. Secretaria da Habitação. (2018). Secretário Silvio Torres assina autorização para construção de 1.461 moradias populares em São José dos Campos. São Paulo. Recuperado em 28 de março de 2018, de http://www.habitacao.sp.gov.br/noticias/viewer.aspx?Id=2999

Servidores das Justiças Federais - SISEJUFE. (2012). Pinheirinho: justiça pra quem? Ideias em Revista, 5(36), 20-23.

Singer, P. (1982). $O$ uso do solo urbano na economia capitalista. In E. Maricato (Ed.), A produção capitalista da casa (e da cidade) no Brasil industrial (pp. 21-36). São Paulo: Alfa Ômega.

Singer, P. (2002). Economia política da urbanização. São Paulo: Contexto.

Souza, M., Pimenta, M. P. R. A., \& Carvalho, R. K. M. (2016). Descumprimento do interesse público pelo Estado: uma análise crítica do caso do Pinheirinho. Alethes: Periódico da Graduação em Direito, 6(11), 389-406.

Teixeira, M. M., Fo. (2016). A atuação do poder judiciário nos conflitos de terra: o caso do Pinheirinho. (Dissertação de mestrado). Instituto de Filosofia e Ciências Humanas, Universidade Estadual de Campinas, Campinas.

Trindade, T. A. (2014). Ampliando o debate sobre a participação política e a construção democrática: o movimento de moradia e as ocupações de imóveis ociosos no centro da cidade de São Paulo (Tese de doutorado). Instituto de Filosofia e Ciências Humanas, Universidade Estadual de Campinas, Campinas.

United Nations Committe on Economical, Social and Cultural Rights - UNHCHR. (1991). General comment n.o 04: the right to adequate housing (Art. 11, Para. 1). Geneva: UNHCHR. Recuperado em 18 de maio de 2018, de http://www.unhchr.ch/tbs/doc.nsf/0/469f4d91a9378221c12563ed0053547e

Villaça, F. (2001). Espaço intra-urbano no Brasil. São Paulo: Studio Nobel.

\section{Editor: Rodrigo Firmino}

Recebido: Jan. 06, 2018

Aprovado: Nov. 01, 2018 